\title{
AÇÃO PÚBLICA E COPRODUÇÃO DE POLÍTICAS PÚBLICAS DE MICROCRÉDITO NO BRASIL E NA FRANÇA PUBLIC ACTION AND CO-PRODUCTION OF PUBLIC MICROCREDIT POLICIES IN BRAZIL AND FRANCE
}

\author{
Maria Alice Cabral Maia ${ }^{1}$ \\ Zilma Borges de Souza ${ }^{2}$
}

\section{RESUMO}

Este texto aborda modelos de financiamento de microcrédito no Brasil e na França. A pesquisa analisa os desafios da viabilização do desenvolvimento socioeconômico e impacto local a partir da ação pública para construção e implementação de políticas públicas de apoio ao microcrédito. A metodologia de pesquisa de vertente qualitativa foi realizada por meio de pesquisa documental e de investigação de campo no Brasil e na França, especialmente focalizando agricultores familiares como público alvo destas políticas. Ao longo do texto são discutidos critérios de sucesso para tal interação, pontos críticos para sua viabilidade e as principais lições ou melhores práticas reveladas pelos casos estudados. Os resultados permitiram identificar pontos relevantes para a coprodução de políticas públicas orientadas para a oferta de crédito para o pequeno produtor familiar e mecanismos capazes de mitigar dificuldades recorrentes nos modelos de atuação existentes.

Palavras-chave: Ação Pública. Ação Coletiva. Agricultura Familiar. Microcrédito. Participação Social.

\section{ABSTRACT}

This text discusses microcredit models in Brazil and France. The research analyzes socioeconomic development and local impact from public action action to construct and implement public policies to support microcredit.The qualitative research methodology was carried out through documentary research and field research in Brazil and France, especially focusing on family farmers as a target au- 
dience for these policies. Throughout the text we discuss success criteria for such interaction, critical points for its viability and the main lessons or best practices revealed by the cases studied.The results allowed to identify relevant points for the co-production of public policies oriented to the supply of credit to the small family producer and mechanisms able to mitigate recurrent difficulties in the existing models of action.

Keywords: Public Action. Collective Action. Family Farming. Microcredit. Social Participation.

\section{INTRODUÇÃO}

Este trabalho aborda a interação entre poder público e sociedade civil para a implementação de microcrédito produtivo orientado para agricultores familiares. Propõe-se como objetivo geral compreender a ação pública proveniente da interação entre poder público e sociedade civil na formulação e implementação de políticas públicas de microcrédito por meio de estudo de casos no Brasil e na França.

O estudo da experiência francesa se refere a um modelo já implementado e direcionado para a produção agrícola de pequenos produtores, que atuam no beneficiamento de produtos agrícolas e em mercados relacionados ao meio ambiente e à sustentabilidade. $\mathrm{O}$ estudo brasileiro aborda um caso específico, que envolve a política pública formulada em um pequeno município. A perspectiva de análise foi centrada nas formas de interação entre o setor público e organismos representantes da sociedade civil e comunidade local na França e no Brasil, e buscou identificar pontos convergentes e divergentes entre as experiências estudadas, sem uma proposta de estudo comparativo.

$\mathrm{O}$ microcrédito tem se tornado, com frequência, uma alternativa para públicos excluídos de outras modalidades de financiamento por razões como a incapacidade de fornecer garantias, a baixa renda, a informalidade do negócio ou, até mesmo, não ter conta bancária em uma instituição financeira tradicional.

$\mathrm{O}$ enfoque central neste trabalho é dado à modalidade do microcrédito produtivo orientado, apresentado como alternativa de política pública para enfrentar a exclusão do sistema financeiro. $\mathrm{Na}$ modalidade de microcrédito produtivo o crédito se destina a uma finalidade específica, como micro empreendimentos ou produção agrícola, por exemplo, sendo, comumente, destinado à compra de insumos ou de bens de capital para a produção. Já quando definido como 'orientado', a modalidade supõe a existência de um agente de orientação que, em alguns casos, pode ser o próprio agente de crédito que, além de avaliar a concessão do crédito, acompanha a sua utilização pelo tomador, garantindo que o mesmo seja realizado.

A escolha de agricultores familiares, micro empreendedores e empreendedores informais se justificativa pela ênfase dada pelas políticas públicas de microcrédito para este público e pela possibilidades de coprodução que tem sido incluídas nestas construções. O financiamento de produção agrícola tem envolvido, nos dois países, alternativas de crédito que se originam de fontes públicas, de organização popular e de fontes privadas, como grandes bancos que vem se interessando pelo tema.

Considera-se que a ação pública proveniente da interação com organizações e coletivos que atuam nestas temáticas pode maximizar os impactos positivos da ação governamental. Neste 
sentido, a participação da sociedade civil, atores interessados, as organizações do terceiro setor, de origem popular e comunitária têm um papel relevante, voltadas para o bem comum. Em menor nível, essa interação pode impactar o momento da implementação, desde a orientação até ao acesso ao público alvo. Em estágios mais avançados de interação, tais organizações podem coproduzir com o poder público desde o momento da formulação das políticas públicas, reestruturando seu modelo e impactando seus resultados.

Como contribuição do estudo, busca-se trazer visibilidade para pontos importantes sobre a ação pública, proveniente da relação entre o poder público sociedade civil e comunidades locais, valorizando experiências reconhecidas por aumentar a entrega de resultados e impacto local, por meio dessa articulação.

\section{METODOLOGIA}

Para este trabalho, realizou-se pesquisa de abordagem qualitativa (CRESWELL, 2010; SPINK, 2013) envolvendo a análise de dados secundários por meio de estudo bibliográfico e análise documental e, adicionalmente, pesquisa qualitativa primária, com entrevistas a atores relevantes para o contexto, como formuladores de políticas públicas, funcionários públicos, professores, habitantes e gestores locais, presidentes de organizações de origem popular e gestores de organizações do terceiro setor. A vantagem de se realizar uma pesquisa por meio

a observação do contexto local está na maior possibilidade de compreender influências, uma vez que se tem acesso às diferentes percepções dos atores sobre o tema tratado (SPINK, 2013).

Para o referencial teórico foram buscados autores que tratam deste tema com uma visão tanto da formulação, como da implementação de políticas públicas de microcrédito. Desta forma, pode-se compreender perspectivas em debate sobre a efetividade destas. Durante a análise de dados secundários, buscou-se, em primeiro lugar, pesquisas quantitativas e qualitativas que pudessem contribuir com uma compreensão mais abrangente sobre o contexto dos ambientes estudados. Complementarmente, utilizou-se estudos sobre casos franceses e brasileiros de políticas públicas de microcrédito, envolvendo a interação entre poder público e organizações da sociedade civil ou do terceiro setor.

$\mathrm{Na}$ França foram realizadas entrevistas com gestores das seguintes organizações: Projeto de Finanças Solidárias-Finansol, coletivo de atores de finanças solidárias, de uma das organizações populares do cluster da região francesa Rhônes-Alpes e oficiais do Parlamento e da Comissão da União Européia, em Bruxelas (Bélgica), visando à maior compreensão do papel da União Européia no contexto estudado. Para vivência e conhecimento do contexto agrário francês, realizou-se visita a agricultores e produtores da região de Reims e Champagne, que permitiu a coleta de informações acerca da característica de atuação coletiva dos agricultores franceses. Essa etapa visou à compreensão do contexto político e social local, formando assim o corpus para análise de boas práticas nas políticas públicas (BAUER; AAARTS, 2007). Ao longo da pesquisa, para obter uma maior compreensão do modelo francês, se abordou o modelo de política pública de microcrédito no país, preterindo o aprofundamento em um caso exclusivo, mas realizando o contato com diversos atores e casos relevantes. 
O segundo momento da pesquisa de campo realizou-se em Julho de 2016, no Brasil, por meio da observação do processo de formulação de uma política pública municipal de microcrédito no município de Timon, no Maranhão. Nesse contexto, foram realizadas entrevistas semiestruturadas e observações não participantes com atores relevantes para os casos estudados, como formuladores e implementadores das políticas públicas e gestores de organizações populares, além de líderes comunitários, autoridades religiosas, servidores públicos e a comunidade local, que seria, potencialmente, beneficiada pela implementação da política. A pesquisa em campo no Brasil envolveu também, além de entrevistas, visitas a comunidades rurais e participação em reuniões entre gestores públicos do município e reuniões entre membros de organizações da sociedade civil. Assim, durante a pesquisa foram catalogados informações e materiais sobre relações entre programas públicos e organizações populares ou do terceiro setor, em ações orientadas ao microcrédito produtivo orientado, buscando, exclusivamente, iniciativas que, por meio de seu modelo de atuação almejem contribuir para o atendimento das necessidades financeiras de empreendimentos produtivos.

A partir dos dois primeiros momentos de pesquisa, a terceira etapa constituiu-se, então, pela análise das observações e materiais coletados, a fim de elaborar conclusões relevantes acerca da formulação e implementação dos modelos de políticas de microcrédito.

\section{REFERENCIAL TEÓRICO}

\subsection{O CRÉDITO PÚBLICO E O FINANCIAMENTO DA PRODUÇÃO}

Os Bancos Comunitários são uma das principais formas de microcrédito reconhecidas no país. Eles são projetos de apoio a economias populares que incentivam a geração de trabalho e renda, promovendo a economia solidária. O Programa Nacional de Microcrédito Produtivo Orientado (PNMPO) foi instituído pela Lei 11.110, de 25 de abril de 2005,com os seguintes objetivos gerais: incentivar a geração de trabalho e renda entre os micro empreendedores populares; disponibilizar recursos para o microcrédito produtivo orientado; e oferecer apoio técnico às instituições de microcrédito produtivo orientado, com vistas ao fortalecimento institucional destas para a prestação de serviços aos empreendedores populares (MTE, 2018)

Este programa definiu o marco legal para o microcrédito produtivo, incluindo a regulamentação para o repasse de recursos dos bancos para instituições de microcrédito. O programa prevê o atendimento das necessidades financeiras de pessoas físicas e jurídicas empreendedoras de atividades produtivas de pequeno porte, e inovou na proposição de uma metodologia baseada no relacionamento direto com os empreendedores no local onde é executada a atividade econômica.

Uma importante alteração foi a realizada em 2010, visando ampliar o número de agentes financeiros que atuavam com a população de baixa renda e fortalecer a relação com os bancos comunitários. Em 2019 são 103 bancos comunitários no Brasil (INSTITUTO BANCO PALMAS, 2019). ${ }^{3}$

\footnotetext{
3 O Programa vem sendo ajustado por diversas resoluções, sendo a mais recente a resolução no. 4.713 de 28 de março de 2019 que trata do direcionamento de recursos para essas operações.
} 
Em relação as outras formas de crédito público e financiamento da produção para pequenos agricultores, dentro das linhas de crédito do Plano Safra ${ }^{4}$, destacam-se as linhas ECO e Agroecologia, com investimentos em assistência técnica, representando o aumento da assistência para dois milhões de famílias, abrangendo todo o país.

No Brasil, no âmbito do microcrédito para a agricultura familiar, as principais iniciativas estão relacionadas ao Pronaf (Programa Nacional de Fortalecimento da Agricultura Familiar), ao Programa de Aquisição de Alimentos (PAA), que liga a oferta de crédito ao acesso ao mercado, e ao Plano Safra. Ambos completaram quinze anos em 2018. Segundo o Anuário Estatístico do Crédito Rural (2016), cerca de $77,86 \%$ dos contratos de crédito rural fornecido a produtores e cooperativas é oferecido por bancos federais. Já as cooperativas de crédito representam 12,34\%. Em valores, os dois tipos de instituição representam $54,15 \%$ e $9,85 \%$ do total do país, respectivamente.

Conforme explicitam Abramovay e Junqueira (2004) uma experiência de referência é a operada entre o Sistema Cresol de Cooperativas de Crédito Rural e o Programa Nacional de Fortalecimento da Agricultura Familiar-PRONAF, que, ao se articularem, conseguem interagir, contribuindo para uma produção agrícola sustentável. Para os autores, desde a prestação de serviços financeiros à intermediação de transferência de renda ou subsídios, essas articulações entre os diferentes setores da economia são capazes de fortalecer ambas as instituições (ABRAMOVAY; JUNQUEIRA, 2004).

Neri (2008) estudou o caso do Crediamigo, programa do Banco do Nordeste (BNB), para entender os impactos do microcrédito para autônomos e microempresários. Dentre os resultados, percebeu-se o aumento real de $30,7 \%$ no lucro operacional (equivalente à renda do trabalho, para autônomos). Já o lucro bruto aumentou 35,1\%. Além disso, cerca de 60,8\% dos beneficiários que se situavam abaixo da linha da pobreza ascenderam, saindo dessa condição. No mesmo estudo, o autor aborda o potencial do Nordeste para o microcrédito: com mais de quatro milhões de profissionais autônomos ou microempresários empregadores. A região se destaca por seu crescimento do acesso ao crédito produtivo: de 3,97\% para 6,27\%, taxa de crescimento superior a outras cidades do país.

Para a aplicação de políticas públicas, as organizações da sociedade civil e do terceiro setor podem funcionar como elemento facilitador. Devido à sua grande compreensão da realidade local, sua maior proximidade de atores locais e, inclusive,seu nível de influência, tais organizações podem se tornar elemento relevante para todas as etapas da política pública: da formulação à avaliação dos resultados. Quando se fala do microcrédito, e, especialmente, no âmbito dos bancos comunitários, essas organizações já estruturadas podem se tornar fundamentais, pela formação do senso de coletivo.

\section{Estudo de caso - O microcrédito para a produção agrícola familiar no Brasil e na França}

Neste tópico serão apresentadas as observações de campo, seguindo primeiramente uma linha descritiva acerca da realidade local, do contexto investigado e do processo de implementação (na experiência francesa) ou do processo de formulação (no caso brasileiro) da política pública.

\footnotetext{
${ }^{4}$ O Plano Safra atualmente vinculado ao Ministério da agricultura, Pecuária e Abastecimento reúne um conjunto de políticas públicas que abrangem os serviços de Assistência Técnica e Extensão Rural, crédito, seguro da produção, garantia de preços, comercialização e organização econômica das famílias residentes no campo.
} 
Os casos de estudo franceses envolvem a organização de clusters e redes de pequenos produtores com as mais diversas finalidades produtivas e histórico de programas integrados para o financiamento da produção agrícola sustentável. Dentro do quadro de crise econômica atual, os encaminhamentos dados a tais questões e o desafio de manter a continuidade das operações e programas trazem novas contribuições ao quadro. O país destaca-se também por políticas públicas delegativas, envolvendo intensamente os níveis locais, inclusive por meio da participação de organizações do terceiro setor ou de organizações da sociedade civil.

O caso brasileiro envolve a implementação de projetos-piloto em duas realidades distintas. Por essa razão, a etapa descritiva buscará trazer observações mais detalhadas dos dois públicos beneficiários. Após essa descrição, será realizada análise, apresentando uma comparação entre os dois casos.

\subsection{AS POLÍTICAS DE MICROCRÉDITO NA FRANÇA}

\subsubsection{O contexto estudado}

O contexto político francês é constituído, historicamente, por uma forte presença do Estado como 'protetor' da sociedade. Para compreender o serviço público francês, considera-se dois grupos principais: os servidores da linha de frente e o alto escalão, sendo este último formando nas Grandes Écoles e com posterior experiência nos 'Grands Córps', geralmente compondo altos escalões de ministérios ou conselhos, além de corpos diplomáticos ou de Prefeitos, por exemplo. Cada uma dessas divisões abrange um nível de responsabilidade, conforme sua extensão territorial. As regiões, por exemplo, atuam sobre o desenvolvimento econômico e social, enquanto as comunas têm atuação sobre assuntos mais pontuais de seu território. É neste nível local que se articulam adaptações das decisões do Estado francês para uma implementação mais adequada à realidade.

\subsubsection{O Modelo da Política Pública Delegativa}

Desde meados da década de 90, o Estado francês vem se baseando em uma metodologia de Desenvolvimento Local Orientado à Comunidade (DLOC) que, conforme informativo da própria Comissão Européia (2013a), tem como objetivos principais: 1) incentivar as comunidades locais a desenvolver abordagens integradas participativas; 2) gerar capacidade comunitária e incentivar a inovação; 3) promover a propriedade comunitária; e 4) apoiar a governança multinível. Este último objetivo é explicado, no mesmo informativo, como "[abrir] caminho à total participação das comunidades locais no desenvolvimento da implementação de objetivos da UE em todas as áreas". Essa descrição vem a introduzir o modelo apresentado posteriormente como "Política Pública Delegativa" ou "Finanças Delegativas", por um dos professores entrevistados, do Instituto de Estudos Políticos de Paris (Science Po Paris).

A Comissão Européia se reúne com os representantes de seus países membros, e as negociações entre cada governo e a Comissão resultam no desdobramento da estratégia européia em programas públicos nacionais, coesos com a estratégia do bloco e capazes de atingir os objetivos do mesmo. A essência da política pública delegativa está no desdobramento das responsabilidades e da tomada 
de decisão em diversas instâncias, do Estado às comunas. O Estado francês, ao adotar uma estratégia macro ou implementar um programa, o desdobra para suas regiões, que, por sua vez, indicam os departamentos em que o DLOC será aplicado. Finalmente, são indicadas as comunas e os programas que serão beneficiados.

É no nível local que se definem os critérios de seleção para beneficiários e as estratégias de implementação do programa. Uma estratégia de desenvolvimento que parte da instância maior de governo busca alcançar a qualidade, então, de estratégia de desenvolvimento local. Na prática, é como se a instância maior de governo inferisse apenas sobre as diretrizes gerais, permitindo certa margem de manobra para abordagens locais. Para os fundos estruturais, por exemplo, cada Prefeito Regional age como Autoridade Administrativa dos programas. A exceção é para a região de Alsace, onde o Conselho Regional atua como Autoridade Administrativa (COMISSÃO EUROPÉIA, 2015). Assim, cada instância para a qual o programa é desdobrado possui capacidade de inferir sobre as melhores condições de implementação, o melhor público beneficiário e, em alguns casos, até os perfis de atividades mais adequados à região ou à categoria.

Segundo esse modelo, os Estados-Membros e a União Européia dividem sua responsabilidade, sendo a Comissão Européia responsável pela definição das diretrizes dos programas e das linhas de avaliação, além do controle da execução orçamentária. Os Estados-Membros e suas instâncias inferiores se tornam responsáveis pelas parcerias locais e regionais, além da seleção dos projetos apoiados. Um dos fundos envolvidos no programa de 2007 a 2013 foi o Fundo Europeu de Desenvolvimento Regional (no inglês, ERDF), que atendeu, ao todo, 31 programas operacionais. No período, três instrumentos foram criados para estreitar as relações dos Estados-Membros com instituições financeiras como o Banco Europeu de Investimento: Assistência Conjunta para o Apoio a Projetos nas Regiões Européias, Recursos Europeus Conjuntos para Micro e Médias Empresas e Apoio Europeu Conjunto para Investimentos Sustentáveis em Áreas Urbanas (do inglês, denominados de Jaspers, Jeremie e Jessica, respectivamente).

Durante o cascateamento das políticas públicas até ao nível local, nas comunas, além de projetos específicos, outros atores podem pertencer ao grupo de beneficiários dos fundos europeus. Tais atores são as organizações da sociedade civil e as organizações do terceiro setor. Surgem então as cooperativas de crédito e as organizações coletivas.

Um exemplo estudado foi o cluster da região de Rhones Alpes, por meio de entrevista com o seu Diretor de Desenvolvimento e Ações Internacionais. O cluster atua no apoio a micro e pequenos empreendimentos de beneficiamento de produtos primários, produções orgânicas, energia, tecnologia e outros mercados relacionados à sustentabilidade. A organização coletiva recebe o financiamento dos fundos europeus, caracterizando o apoio financeiro regional, e então se organiza para orientar mais de 180 MPEs participantes, analisando tendências de consumo e gaps da oferta e organizando feiras e eventos para a promoção de seus membros. Seu foco é a capacitação e o acesso à comercialização (inclusive para exportação), e no âmbito da agricultura atendem àqueles que desejam deixar de ser apenas produtores. Segundo o Diretor são mais de 2600 agricultores, que iniciam seus próprios empreendimentos, abrangendo diferentes modelos de negócio, como linhas de cosméticos orgânicos. Até 2014, o cluster havia recebido mais de 900 mil euros de auxílio financeiro das regiões, diretamente repassados às empresas participantes. 


\subsubsection{A percepção e o impacto do Modelo Delegativo pelos Atores Entrevistados}

O modelo delegativo sugere uma releitura ao modelo tradicional de implementação de políticas públicas: as organizações coletivas se tornam, em nível local, co-gestoras da política ou do programa, ganhando importância política ao adquirir o direito à tomada de decisão sobre a implementação da política no nível local. Ao delegar a tomada de decisão sobre o financiamento, o Governo Francês flexibiliza as ações, aumentando a visibilidade de atores menores, como agricultores familiares, micro empresários e PMEs. Para aqueles que atuam coletivamente, por meio organizações do terceiro setor ou sociedade civil organizada, o espaço se torna ainda maior, com representativo ganho em autonomia de tais organizações.

O que se percebeu nas falas dos entrevistados foi o ganho em capilaridade e escala, uma vez que, ao nível local, as organizações são capazes de atingir públicos mais remotos ou com pouca representatividade nacional, mas grande representatividade local. Além disso, a percepção dos entrevistados é de que as organizações agregam à implementação maior conhecimento da realidade local, permitindo uma adequação da mesma e um direcionamento capaz de atender melhor às necessidades de seu público e do mercado local, quando aplicável.

Segundo publicação da Comissão Européia (2013), um exemplo de projetos beneficiados por tais políticas regionais é o Energivie, que visa à introdução e promoção do uso de energias sustentáveis em setores como turismo e agricultura, além de projetos em temáticas como inovação, apoio a empresas, meio ambiente, desenvolvimento urbano e rural, turismo e cultura, e energia. Ao todo, foram apoiados 140 mil projetos franceses, sendo destinados 4,2 bilhões de Euros a Pesquisa e Desenvolvimento e Inovação e 1,4 bilhões de euros para a promoção do empreendedorismo e de pequenas e médias empresas.

Apesar da percepção positiva e dos resultados demonstrados pelo DLOC, foi possível notar também, nas falas e entrevistas, práticas de microfinanças e políticas concorrentes aos programas públicos, o que pode indicar a existência de gaps na oferta pública de microcrédito, em suas diretrizes ou em seu modelo de implementação. O primeiro exemplo vem do próprio cluster de Rhones Alpes, mencionado anteriormente. Durante a entrevista, além de encontros e orientações voltadas para o recebimento do crédito público, foram mencionadas parcerias com bancos privados, direcionadas à oferta de linhas de financiamento a taxas mais baratas.

O segundo exemplo refere-se ao modelo de finanças solidárias, que promove investimentos em empresas ou projeto cujo negócio (ou finalidade) beneficie, diretamente, a sociedade, prezando pelo desenvolvimento sustentável. Foi possível entrevistar, durante a permanência na França, o responsável pela Missão de Financiamento Solidário no Finansol. Na época o modelo, ainda incipiente no Brasil, já começava a ganhar espaço na França, e, segundo Brebion, a crise econômica era um estímulo para seu crescimento, utilizando-se do argumento de que, em um momento em que a maioria dos investimentos é de retorno incerto, as finanças solidárias garantem, além do retorno financeiro, o retorno em capital social para comunidades necessitadas.

Por fim, um último exemplo de conceito de financiamento concorrente ao financiamento público, discutido tanto pelo Diretor de Desenvolvimento e Ações Internacionais do Cluster de Rhone-Alpes, como por participantes da Sustainable Business Conference 2012, foram os fundos de Venture 
Capital (em francês, Societé de Capital Risque). O Diretor em Rhone-Alpes chegou a mencionar, como exemplo, a Garrigue, organização de Venture Capital que apóia a criação ou o desenvolvimento de empresas que tenham como preocupações principais o desenvolvimento social ou do meio ambiente. A Garrigue é também um dos membros-fundadores do Finansol.

\subsection{AS POLÍTICAS DE MICROCRÉDITO NO BRASIL}

\subsubsection{O Contexto estudado}

A experiência brasileira aqui abordada aconteceu na região do município de Timon, no estado do Maranhão. Localizado a aproximadamente 430 quilômetros da capital, o município é o quarto maior de seu estado em Produto Interno Bruto (PIB) e o mais populoso, com 155.460 habitantes em uma área de $1.743 \mathrm{~km}^{2}$, conforme o Censo 2010 do Instituto Brasileiro de Geografia e Estatística (IBGE). O censo ainda traz informações sobre a economia do município, essencialmente fundamentada no setor de serviços, responsável por aproximadamente $80 \%$ de seu PIB. O crescimento do comércio, contudo, também é considerável.

A atenção para a necessidade de geração de emprego e renda em Timon é influenciada, também, por um aspecto geográfico do município: Timon se localiza a apenas três quilômetros da capital do estado vizinho, o Piauí. Com um nível de desenvolvimento econômico superior e sendo considerada o pólo de saúde da região, Teresina tem impacto fundamental sobre as finanças e a economia de Timon. Separados apenas pelas margens do Rio Poty (cruzados de barca ou pela ponte, a pé, de carro, motocicleta, bicicleta ou ônibus), os fluxos entre municípios vão de mercadorias a recursos financeiros. Foi possível perceber que parte da força de trabalho de Timon (inclusive no setor público) é residente em Teresina, assim como grande parte dos moradores de Timon desloca-se até Teresina para trabalhar, principalmente nos setores de construção civil, limpeza e segurança privada.

Tal aspecto é ressaltado, principalmente, nos discursos dos gestores públicos do município. Para compreender melhor o contexto dos dois projetos pilotos da política pública, é necessário compreender mais profundamente as características das comunidades da zona rural.

O município de Timon possui, em seus arredores, cerca de 300 comunidades rurais, com aproximadamente 15 famílias por comunidade. As realidades das comunidades são bem parecidas entre si, havendo apenas três casos de maior diferencial, por seu desenvolvimento econômico. Durante as visitas ao Sindicato dos Trabalhadores e Trabalhadoras Rurais de Timon (STTRT), foi possível entrevistar presidentes e representantes de associações de moradores de algumas destas comunidades. Na maioria, os relatos trazem uma cultura de produção individualizada (cada família produz em seu próprio quintal) e problemas comuns, como irrigação, falta de capacitação, falta de orientação sobre culturas adequadas, acesso à crédito e perda da safra por questões climáticas e de infraestrutura. Para a maioria das comunidades, os únicos meios de transporte existentes são o ônibus e a bicicleta. Em alguma delas, tomar o ônibus para vir a Timon significa realizar um trajeto de quatro horas por trecho.

Quando questionados sobre meios de comunicação, os agricultores revelaram que possuem de um a dois celulares pré-pagos por família e que utilizam o celular somente para chamadas, pois têm medo de enviar SMS por não compreender o modelo de cobrança das mesmas. Disseram também que 
utilizam o serviço principalmente quando vêm a Timon, pois em muitas comunidades há problemas de infraestrutura, não havendo sinal, ou este sendo restrito a áreas mais altas. Em relação à organização coletiva, os relatos também foram semelhantes, mencionando dificuldades para desenvolver projetos coletivos e, até mesmo, para conseguir quórum para reuniões de rotina. Dentre os motivos apontados estão o desinteresse espontâneo (e a mentalidade de progresso individual, sem necessidade de associação a semelhantes) e a descrença em soluções coletivas, devido a um histórico de promessas do poder público não cumpridas e de projetos descontinuados ou mal sucedidos.

Dentre as comunidades, São João dos Marrocos e Bambu têm perfis muito distintos. A primeira é considerada por servidores públicos e outros líderes comunitários como um caso de sucesso entre as comunidades, tida como a mais desenvolvida da região, enquanto a segunda é o retrato da realidade mais comum, de pobreza e abandono. De fato, São João dos Marrocos apresenta características impressionantes: os jovens trabalham em uma cerâmica que foi construída há cerca de 20 anos por "Seu Mundico", o líder da comunidade. Os mais velhos trabalham no campo: os homens pescam (há um tanque de peixes na comunidade) e são responsáveis pela produção de quiabo, e as mulheres cuidam de uma horta. Toda a produção é feita em área coletiva (em uma terra arrendada), e os custos, como eletricidade, são divididos entre todos, e cada morador cede uma parte da produção para a associação. As casas da comunidade são de alvenaria, com construções complexas, de mais de dois cômodos. Muitos dos residentes são jovens (que deixam de procurar emprego na cidade, uma vez que podem trabalhar na cerâmica). Ao conversar com Seu Mundico e os habitantes locais, percebe-se uma forte influência do líder na construção do senso do coletivo. Firme, o discurso dele sobre a participação da comunidade parece nem presumir a abstenção de membros. Uma das senhoras da comunidade explicou: "Pode não ir na presença, mas tem que ir no dinheiro." (sic). E, ao serem questionados sobre as razões para o desenvolvimento, os habitantes afirmam com frases como "É a união". Um dos habitantes (que mora somente com sua esposa) afirmou possuir uma renda familiar de 700 a 1500 reais, conforme produção.

A primeira diferença para a comunidade do Bambu se encontra no modelo de produção: cada família planta sua cultura em seu próprio quintal (terreno geralmente inferior a um hectare), e não coletivamente. O presidente da associação da comunidade queixou-se sobre as dificuldades em unir os habitantes em um projeto ou ação coletiva. As casas são de pau-a-pique, sendo que a maioria possui apenas um cômodo. De carro, o tempo de deslocamento até o centro de Timon é de 30 minutos, mas somente um dos moradores possui veículo próprio. Para o restante, o trajeto até a cidade é feito de ônibus ou bicicleta.

Durante a pesquisa de campo, foi possível entrevistar comerciantes e agricultores sobre sua relação com o crédito, na intenção de compreender questões culturais e potenciais oportunidades ou barreiras já existentes na região. Na região central do município há agências de grandes bancos nacionais, como Caixa Econômica Federal, Banco do Brasil e Banco Itaú, além de uma agência do Banco do Nordeste do Brasil, um ponto de atendimento do CrediAmigo e uma grande concentração de estabelecimentos de oferta de crédito, anunciando, em alguns casos, a disponibilização de crédito para negativados e, inclusive, para o pagamento de outras dívidas.

Já no caso rural, durante as conversas na comunidade do Bambu, alguns moradores chegaram a relatar o uso do crédito público pelo PRONAF, especialmente por meio do AgroAmigo. Mas para 
grande parte, especialmente entre os mais velhos, a palavra crédito foi recebida com perceptível surpresa e receio. Quando perguntados sobre a razão, a justificativa é sempre a mesma: medo de endividamento. Outro discurso dos moradores do campo era referente à oferta e ao acesso ao crédito. Segundo eles, há pouca oferta e, quando esta é existente, os requisitos são muitos, dificultando o acesso.

Segundo técnicos da Secretaria da Agricultura, porém, o principal requisito para acesso ao crédito é a DAP (Declaração de Aptidão ao Pronaf), que é um documento exigido pelo Governo Federal, e muitos agricultores têm conseguido acesso ao mesmo. Ainda segundo a visão dos técnicos, o que falta é o interesse em produzir, a dedicação e o emprego correto do auxílio recebido. Chegaram a relatar alguns casos, como o de uma comunidade que recebeu da secretaria kits de irrigação, e ao invés de instalá-los, revendeu. Exemplificaram também o caso de uma comunidade que recebeu subsídios para a compra de equipamentos e insumos para a produção de Caju, e aproveitavam somente o suco para a cajuína, descartando outras partes como a castanha, que poderiam ser beneficiadas e ser revendidas com ainda maior valor agregado. Segundo os técnicos, neste mesmo caso houve também desinteresse na continuidade do negócio: uma vez que a produção acabou, não houve parte da receita reinvestida para a compra de mais insumos, e esta foi gasta com fins não produtivos.

Mas também no campo é possível encontrar casos de sucesso, como o da comunidade de São João dos Marrocos, já mencionado anteriormente. No caso, iniciado há cerca de 20 anos, o líder comunitário Seu Mundico, uniu cerca de 10 moradores para a tomada de um valor maior de crédito. Ao invés de cada um tomar os quase dois mil reais e investir individualmente, investiram os 20 mil reais para preparar a terra e organizar a produção, que é feita coletivamente, além da produção da cerâmica. A partir daí, os agricultores continuaram renovando o crédito, mas para a expansão da produção e da cerâmica.

\subsubsection{O Projeto de Política Pública}

O projeto de Política Pública estudado era uma proposta da Secretaria Municipal de Desenvolvimento Econômico e Turismo (SEDETUR). Confirmando as características do governo, a SEDETUR tem, entre seu pessoal, técnicos muito jovens, mas já com experiência prévia no setor público. Já entre os altos gestores é possível encontrar mestres, como o então secretário, com ainda pouca experiência profissional relacionada ao setor público.A gestora responsável pela política é a Diretora de Acesso ao Crédito e Comercialização. Com experiência no setor privado, mas sem atuação prévia no setor público, ela foi convidada a participar do corpo da SEDETUR pelo secretário nomeado.

Como gestora pública do município de Timon, um dos primeiros desafios apresentados à gestora foi a ideia do Banco Comunitário. Natural de Timon, o secretário já conhecia a questão da mobilidade de recursos financeiros entre o município e Teresina, e encarava isso como uma das discussões prioritárias do governo, tendo imaginado o Banco Comunitário como um potencial mitigador do problema. A proposta do secretário considera o Banco Comunitário como um potencializador do desenvolvimento econômico regional, e acredita que, uma vez que este esteja estabelecido como agente de microcrédito local, será possível inserir na economia uma moeda social. Moeda social é uma moeda com circulação e poder de compra restritos a uma localidade específica. Em grande parte dos casos ela é criada como modo de incentivar que a renda de uma determinada comunidade se mantenha 
circulando dentro da mesma. Ao assumir a diretoria, a gestora se tornou responsável, portanto, pelo desenvolvimento do projeto do Banco Comunitário e da moeda social.

No caso estudado, há ainda uma característica particular do projeto, que o diferencia de outros projetos com o mesmo objetivo: a moeda social seria eletrônica. Para o secretário, essa restrição se deve ao alto custo do papel moeda e aos riscos de danificação do papel, que podem comprometer a relação lastro/circulação. Legalmente, a proposta tem seu embasamento na Medida Provisória $615 / 2013^{5}$, que dá autonomia ao Banco Central para regulamentar os 'arranjos de pagamento', abrindo espaço para meios de pagamento eletrônicos.

O Banco comunitário, além de agente de microcrédito, teria uma função a mais: a orientação do uso do crédito, que abrangeria, inclusive, a capacitação em gestão para os empreendedores e agricultores beneficiados. A moeda social eletrônica circularia por meio de celulares e smartphones, mas ainda não havia consenso sobre o formato definitivo dessa circulação: se por meio de $\mathrm{SMS}^{6}$, aplicativo mobile ou se pela utilização de créditos de celular pré-pago como moeda, seguindo o modelo queniano da Safaricom ${ }^{7}$, que se tornou caso de sucesso em microcrédito e mobile payment. Outra característica até então sem definição se refere à qualidade do crédito: se este seria oferecido somente para fins produtivos ou se abrangeria também fins não produtivos.

\subsubsection{A Percepção e o Impacto da Formulação da Política Pública de Microcrédito}

A formulação da política pública iniciou-se, como explicado anteriormente, pelo trabalho do secretário, sendo assumida pela gestora logo no início do mandato. Segundo os relatos da gestora, os primeiros meses tinham sido utilizados para pesquisa e aquisição de contatos, por meio de presença em eventos e cursos, por exemplo. Além disso, ela trabalhou no desenvolvimento da formulação do projeto e seu planejamento estratégico, interagindo também em outras ações da SEDETUR. Durante esta etapa, a gestora fez contato com organizações dos diversos setores, como universidades, centros de pesquisa, órgãos federais para o desenvolvimento econômico e organizações internacionais de financiamento de projetos para o desenvolvimento econômico. Foi possível acompanhar a segunda etapa do processo: a visita da gestora às organizações da sociedade civil para a apresentação do projeto. A apresentação foi seguida de uma discussão com os agricultores, e houve pouco interesse em discutir a proposta específica, com foco maior na discussão da atenção dada pelo poder público em geral.

O que se pôde perceber, pela discussão, é que, para muitos que participaram não há uma diferenciação entre as instâncias ou entre os diferentes órgãos públicos. As críticas revelaram, principalmente, uma descrença em relação à eficácia do poder público, seja devido ao número de projetos apresentados e não cumpridos, ou pelo difícil acesso e complexidade dos requisitos exigidos pelos que se realizam de fato. Já os presidentes de associações demonstravam interesse na proposta, com esperança de que esta pudesse mudar a realidade de sua comunidade.

5 Câmara dos Deputados. Projetos de Lei e outras Proposições. <http://www.camara.gov.br/proposicoesWeb/fichadetra

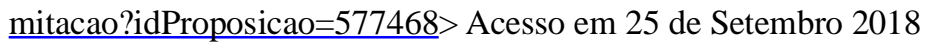

6 Short Message Service, ou Serviço de Mensagens Curtas, padrão de comunicação de texto entre celulares.

7 Após perceber o comportamento de consumo dos usuários de celulares pré-pago Safaricom, empresa de telefonia celular queniana, lançou a primeira conta de celulares, a M-PESA, que aumentou o acesso da população a serviços financeiros formais. (FSD KENYA, 2011) Disponível em: <http://www.fsdkenya.org/finaccess/documents/11-06-27 finaccess 09 results analysis.pdf $>$. Acesso em 16 de Novembro de 2018. 
Por fim, a Escola Mãos Dadas foi a última apresentação pública do projeto presenciada (houve ainda algumas apresentações individuais, que serão tratadas adiante).Ali, duas professoras apresentavam o projeto a um grupo de cerca de 400 pais de alunos, acompanhadas pela diretora da SEDETUR e pelo Padre.Era o dia de reunião de pais e professores, e cada período (matutino e vespertino) se iniciava com a fala do Padre no auditório. A apresentação pelas professoras foi bem recebida pelos pais. Ao questionar sobre o apoio ao projeto, poucas mãos não se levantaram. As questões apresentadas eram pontuais, e especificamente sobre o funcionamento do Banco Comunitário. Apesar de positiva, é preciso tomar a aceitação com cautela. Quando solicitado que aqueles que não levantaram a mão se manifestassem, ninguém se apresentou. O apontamento, aqui, é para a relação de dependência que se tem: as regras da escola são rígidas, e as vagas são disputadas por alunos de toda a região. Muitos pais vêem a escola como a oportunidade de acesso de seus filhos a uma formação de qualidade. E talvez por essa razão, possa haver uma construção de respeito e influência que seja limítrofe à obediência e subordinação, influenciando a discussão de projetos como esses.

Em paralelo a essas apresentações, durante o mês de julho houve também reuniões com outros gestores da SEDETUR, outros secretários municipais e com o prefeito, para a apresentação do projeto. De modo geral, todos apresentaram aceitação e disposição para discutir o projeto. Contudo, grande parte afirmou não ter conhecimento do projeto até o momento, mesmo que em linhas gerais. Em uma das secretarias, o gestor explicou que o município era altamente dependente de recursos federais, e que por essa razão um projeto desse porte deveria ser amplamente comunicado entre as secretarias.

\subsection{ANÁLISE COMPARADA DAS DUAS EXPERIÊNCIAS ESTUDADAS}

A experiência francesa se dá em um momento de recuperação econômica e de contenção dos excedentes agrícolas, em que o estímulo ao empreendedorismo é utilizado, inclusive, como modo de deslocar a atividade econômica do campo da produção primária para o beneficiamento de produtos e desenvolvimento de tecnologias. O modelo de política pública do país se constitui a partir de um processo de formulação centralizado na União Européia ou no Estado, que se desdobra para as regiões, comunas e, finalmente, tem seus efeitos em projetos de origem comunitária.Verificou-se que, apesar de gerar uma percepção positiva acerca da autonomia das comunas e regiões para a alocação dos recursos, permitindo uma adequação à realidade local, o contexto francês revela o fortalecimento de alternativas de financiamento concorrentes às políticas públicas, o que pode indicar que ainda existe espaço para o desenvolvimento destas.

O caso brasileiro, por outro lado, traz a realidade de um município cuja economia é altamente dependente de recursos do Estado, mais especificamente dos programas de transferência de renda. O caso estuda a formulação de uma política pública que busca, por meio da criação de uma moeda social que concentre o consumo da população no próprio município, fomentar o desenvolvimento econômico local. Em Timon, o processo de formulação se iniciou com o planejamento e contato com organizações para o financiamento de projetos de desenvolvimento, além de outras organizações de ensino e pesquisa. A etapa seguinte ao planejamento envolveu a interação com outros agentes do poder público e com atores da sociedade civil, como meio de divulgar a política e de buscar apoio que fortalecesse a implementação da mesma. 
Portanto, a partir da etapa descritiva dos casos investigados, é possível identificar três principais fatores de diferenciação entre as políticas francesa e brasileira, sendo eles:as diretrizes da política pública quanto ao seu público e suas consequências; o momento da primeira interação Estado-sociedade e a finalidade deste contato; e a accountability. Estes fatores são comentadas a seguir.

A primeira etapa, portanto, diz respeito às diretrizes da política pública. Na França, a experiência estudada se volta especificamente para públicos determinados, conforme direcionamento estratégico do governo. Considerando a questão dos excedentes, por exemplo, há um direcionamento do financiamento para negócios e projetos que não se limitem à simples produção agrícola. Já no Brasil, o caso estudado previa uma concessão generalizada de crédito, para diferentes públicos e negócios, sem um direcionamento específico por parte do poder público. Quanto às estruturas de generalização ou especificação, ainda não é possível inferir qual o melhor caminho para a política pública, mas esse tópico merece a continuidade de estudos. O modelo brasileiro revela uma menor intervenção do estado no direcionamento da economia, permitindo inferir, inclusive, que para a política pública brasileira o impacto da atuação da linha de frente, a nível local, é maior do que na experiência francesa, cujas diretrizes fornecidas pelo Estado são restritamente específicas.

O segundo ponto de contraste percebido nas diretrizes da política é relativo ao seu impacto sobre a construção do senso de coletivo. O crédito no modelo francês não é cedido a indivíduos, mas a projetos coletivos, que distribuem os recursos entre seus membros ou os utilizam para financiar as ações do próprio coletivo, como capacitação, promoção e acesso e fomento à comercialização. Portanto, há o estímulo à ação coletiva, incentivando o estabelecimento de organizações profissionais e associações, além de coletivos e redes. Esse formato fortalece o desenvolvimento regional, uma vez que tais redes estimulam a troca de experiências, o estabelecimento de novas relações comerciais e o compartilhamento de tecnologia. Já no Brasil, o foco principal é o crédito para indivíduos ou projetos individuais. Apesar de se basear na construção do Banco Comunitário, a política pública formulada prevê que a concessão do crédito por meio deste será realizada para micro empreendedores, pequenas empresas ou a agricultores familiares, individualmente. $\mathrm{O}$ individualismo é característica também em outros programas e políticas de crédito público, como o programa CrediAmigo, frequentemente mencionado durante as entrevistas. Apesar de exigir a organização de um coletivo para a tomada de crédito, se requer que os projetos de cada indivíduo sejam diferentes, deixando ao coletivo uma relação de simples obrigação financeira.

Por meio dos discursos do poder público e das entrevistas com outros atores, como funcionários do Banco do Nordeste, é possível levantar hipóteses sobre os fatores que levam à distribuição da oferta de crédito entre indivíduos. A primeira é do lado da oferta, e se refere à diminuição do risco decorrente da inadimplência: uma vez que se distribui o crédito em diferentes projetos individuais, o risco da carteira de crédito diminui. Uma segunda hipótese é relativa à demanda, e se baseia na construção cultural e histórica da região. As entrevistas com a comunidade e líderes comunitários se referiam, com frequência, a uma construção cultural marcada pela subordinação e pela competitividade entre iguais. Segundo tais relatos, a subordinação se enfraqueceu com a construção da sociedade moderna, mas se manteve a competitividade, evoluindo para graus mais altos de individualismo.

Por ser de formulação centralizada, as políticas francesas tendem a ocupar papéis complementares, totalizando uma ação do poder público capaz de atender diferentes demandas. Já a distribuição 
da formulação em diferentes instâncias e órgãos da administração direta e indireta pode gerar concorrência entre diferentes programas públicos e, inclusive, resultar em uma multiplicidade de oferta para um mesmo beneficiário, fator que, a curto prazo, concentra e diminui o número de beneficiários da totalidade dos programas públicos. No caso brasileiro estudado, por exemplo, a proposta de política pública apresentava, no âmbito da oferta de crédito, uma forte concorrência com outros dois programas fortes na região: o Crediamigo e Agroamigo. A elaboração de programas complementares se torna, portanto, um desafio aos formuladores de política pública, como outra questão de investigação que mereça o desenvolvimento de novos estudos.

Quanto ao momento da primeira interação, no caso brasileiro, o poder público interage com a sociedade desde a formulação da política pública, mantendo uma relação de proximidade com a comunidade. Já no caso francês, o contato é realizado somente no momento da execução da política, e somente a nível regional ou local. A finalidade da interação também diferencia as duas experiências: se no Brasil o alinhamento é buscado como meio de verificar a aceitação e comunicar o projeto, divulgando a ação do poder público, na França o contato é realizado com o objetivo de obter uma maior assertividade na execução da política pública, permitindo em nível local uma "customização" da mesma.

Ambas as posturas revelam pontos de atenção, conforme se acompanha na etapa descritiva. $\mathrm{Na}$ França, sabe-se que essa participação está limitada dentro do escopo já definido pela instância maior, permitindo somente a tomada de decisão sobre a execução em si, como critérios de escolha dos projetos beneficiários e, em alguns casos, a metodologia de monitoramento e acompanhamento. No Brasil, a proximidade antecipada, por meio da divulgação, pode gerar uma perda da credibilidade ou mesmo afetar a confiança (como relatos abordados durante a etapa descritiva), uma vez que o projeto ainda demoraria a ser implementado.

Por fim, em relação à accountability foi possível verificar uma situação bem diferente nos dois casos estudados. O modelo francês de concessão de crédito, apesar de descentralizar a operação, apresentou maior publicidade das informações. Há, por exemplo, guias com descrições completas dos projetos financiados, que podem auxiliar, inclusive na cobrança da prestação de contas por parte da população.As informações quantitativas também estão presentes, com informações sobre distribuição do financiamento por diferentes áreas temáticas de projetos, países e regiões, além de informações sobre indicadores sócio-econômicos desenvolvidos durante a implementação do programa.

No Brasil, como a política de crédito se baseia, majoritariamente, em indivíduos, se torna inviável a publicidade da prestação de contas por beneficiário. Além disso, as avaliações encontradas em pesquisas e outras literaturas sobre o tema dissertam, majoritariamente, sobre aspectos qualitativos. Quando se trata de resultados quantitativos, o sucesso de um programa é relacionado, frequentemente, ao aumento no número de beneficiados ou no valor total de crédito oferecido.

Para ambos os casos, contudo, quando encontrados indicadores relacionados à eficiência, eficácia ou efetividade da política, estes são superficiais, dificultando, por exemplo, a análise comparativa entre beneficiários e não beneficiários do programa, ou seja, uma análise com grupo controle, capaz de diferenciar efeitos macroeconômicos dos resultados reais. 


\section{CONCLUSÃO}

O objetivo deste trabalho foi o de produzir uma análise das etapas de formulação e implementação de políticas públicas brasileira e francesa no âmbito do microcrédito produtivo orientado. Ao apontar aspectos relevantes acerca do relacionamento entre o poder público e a sociedade civil e seus resultados na aplicação das políticas a nível local, pretendeu-se registrar aprendizagens que aumentassem a entrega de resultados por meio de tal interação.

Durante a etapa descritiva foi apresentado o contexto em que se desenvolveu cada experiência, além de um detalhamento dos modelos construídos para formulação, no caso brasileiro, e para a execução, no caso francês. Por fim, a análise abordou os principais pontos de contraste entre as duas experiências, com foco naqueles relacionados ao entendimento do público-alvo e à interação entre este, como sociedade civil, e o poder público. Estas análises permitiram o apontamento de questões para estudos posteriores e que podem revelar oportunidades para melhoria e mitigação de risco na gestão de políticas públicas.

Dentre os pontos observados, deu-se destaque para três questões principais: as diretrizes da política pública em relação ao seu público, o momento e a finalidade da primeira interação Estado-sociedade e a accountability. Da primeira questão, se desdobraram três dicotomias, que apresentam caminhos para a construção da política pública: 1) crédito individual x crédito coletivo; 2) generalização x especificidade do público; e 3) centralização x descentralização da formulação. Em relação ao tópicos mencionados, as observações revelam que há pontos ótimos e pontos a desenvolver em ambos os casos.

No contexto brasileiro registra-se a existência de um número crescente de bancos comunitários e novas intervenções governamentais que ampliaram a oferta de soluções, mas também a complexidade dos modelos de financiamento e crédito para a agricultura familiar sustentável. A partir de meados da década de 90, a operacionalização de linhas de crédito, o surgimento de novos espaços produtivos, junto com a legislação específica, veio concretizando oportunidades de geração de renda e trazendo à luz o debate da agricultura familiar. Percebe-se avanços na busca do poder público por parcerias com a sociedade civil, demonstrando um movimento de conscientização quanto à importância da mesma para a eficácia e a efetividade de políticas públicas. Além disso, a inserção da sociedade civil desde a formulação e a menor rigidez das diretrizes demonstram que há espaço para uma maior inserção da sociedade civil como ator ativo na construção de políticas e programas públicos. Há porém, como mencionado, pontos ainda a desenvolver, dentre estes, o principal se refere à accountability das políticas públicas, que deve ser melhorada a ponto de permitir análises de eficácia e de efetividade, possibilitando, inclusive, a comparação de indicadores entre beneficiários e não beneficiários do programa.

$\mathrm{O}$ estudo da experiência francesa trouxe uma perspectiva de políticas de microcrédito, com um formato quase oposto ao desenvolvido no caso brasileiro. A comparação intensificou, por fim,o entendimento da importância de modelos que estabeleçam formas de diálogo entre as ações da comunidade e as do governo.

No contexto do microcrédito, essas organizações podem vir a gerar inovações na formulação de estratégias e no direcionamento das ações se forem capazes de se flexibilizar e adequar demandas de acordo ao contexto e realidades territoriais. 
O Brasil tem programas inovadores de origem estatal em diversas linhas de financiamento e também vem apresentando experiências importantes com crédito originado de organização popular com base em associativismo e cooperativas. É necessário identificar as diferentes demandas que as regiões brasileiras apresentam e analisar a adequação da aplicação do crédito a estas demandas.

As contribuições que as Instituições de Ensino, Pesquisa e Extensão podem trazer para este campo são diversas e entende-se que os estudos da Administração Pública como campo de conhecimento são cruciais para entender as melhores formas de gestão e de estratégia que atendam as necessidades dos agricultores e de cada região específica, especialmente em contextos de fortes mudanças nas políticas públicas e órgãos gestores federais.

\section{REFERÊNCIAS}

BAUER, M. W.; AARTS, B. A Construção do Corpus: Um Princípio para a Coleta de Dados Qualitativos. In: BAUER, M. W. e GASKELL, G. (Ed.). Pesquisa Qualitativa com Texto, Imagem e Som: Um manual prático. Petrópolis: Vozes, 2007. cap. 2, p.39-63.

BEDUSCHI FILHO, L. C.; ABRAMOVAY, R. Desafios para o Desenvolvimento das Regiões Rurais,.Nova Economia, Belo Horizonte, n. 14, p. 35-70, set./dez. 2004.

BORGES , Z. Inovações no modelo de negócio da Agricultura Familiar brasileira: o caso da Rede Ecovida. In: Colóquio Internacional sobre Poder Local, 2012, Salvador-BA. XII Colóquio Internacional sobre Poder Local, 2012.

BRASIL. O que é a Rede Brasileira de Bancos Comunitários?.Instituto Palmas. Disponível em: <http://www.bancopalmas.org.br/oktiva.net/1235/nota/111263 > , acessado em 25 de Dezembro de 2016.

BRASIL. Relatório de Dados do Programa de Microcrédito - $1^{\circ}$ Trimestre de 2013. Brasília, 2013. Disponível em: <http://portal.mte.gov.br/data/files/8A7C812D3F9B2012013FE3CA513C0 9A6/RELATÓRIO\%20MICROCREDITO\%201\%20TRIMESTRE\%202013.pdf> Acesso em 13 de Novembro de 2018

CENTRO DE POLÍTICAS SOCIAIS FGV. Rio de Janeiro, 2008. Disponível em: <http://www.cps. fgv.br/ibrecps/crediamigo/index.htm $>$ Acessado em 25 de Outubro de 2018.

COMISSÃO EUROPÉIA. Desenvolvimento Local Orientado para a Comunidade: Política de Coesão 2014 - 2020. Comissão Européia. Bruxelas, 2013. Disponível em :<http://ec.europa.eu/regional_policy/ sources/docgener/informat/2014/community_pt.pdf> Acessado em 09 de Novembro de 2018.

COMISSÃO EUROPÉIA. European Cohesion Policy in France. Comissão Européia. Bruxelas, 2009. Disponível em :<http://ec.europa.eu/regional_policy/sources/docgener/informat/country2009/ fr_en.pdf> Acessado em 03 de Novembro de 2018.

COMISSÃO EUROPÉIA. Report Perspectives de l'emploi de l'OCDE: Faire face à la crise de l'emploi. Paris, OCDE. 2009.

COMISSÃO EUROPÉIA. Results of the negotiations of Cohesion Policy strategies and programmes 2007-2013. Bruxelas, 2013. Disponível em : <http://ec.europa.eu/regional_policy/sources/docoffic/ official/communic/negociation/country_fr_en.pdf $>$ Acessado em 03 de Novembro de 2018. 
CONAB- Companhia Nacional de Abastecimento. PAA beneficia mais de 800 mil pequenos produtores em 10 anos. Disponível em: 〈http://www.conab.gov.br/imprensa-noticia.php?id=30305> Acesso em: 05 de Novembro de 2016.

CRESWELL, J. W. Projeto de pesquisa: métodos qualitativo, quantitativo e misto. 3a. ed. Porto Alegre, RS: Bookman Artmed, 2010.

DESER. Departamento de Estudos Sócio-Econômicos Rurais. Boletim do DESER n. 153. [S.I.]: DESER, 2011b. Disponível em <http://www.deser.org.br/boletim.asp.>, acessado em 25 de Agosto de 2016.

FINANSOL. Disponível em: 〈http://www.finansol.org/fr/et-un-collectif.html $>$ Acessado em 13 de Outubro de 2018.

FRANÇA, C. G.; GROSSI, M. E.; MARQUES, V. P. M. A. O Censo Agropecuário 2006 e a Agricultura Familiar no Brasil. Brasília, Disponível em: <http://www.bb.com.br/docs/pub/siteEsp/ agro/dwn/CensoAgropecuario.pdf>, acessado em 30 de Novembro de 2016.

FSD Kenya. Financial inclusion in Kenya: Survey results and analysis from FinAccess 2009. 2011.

Disponível em: <http://www.fsdkenya.org/finaccess/documents/11-06-27 finaccess_09 results analysis.pdf $>$. Acesso em 16 de Novembro de 2018.

INSTITUTO BANCO PALMAS. Rede Brasileira de Bancos Comunitários. Disponível em: https://www. institutobancopalmas.org/rede-brasileira-de-bancos-comunitarios/ Acesso em 16 de outubro de 2019.

IPEA. Desenvolvimento Rural. Instituto de Pesquisa Econômica Aplicada. Brasília, 2016.

IPEA. Instituto de Pesquisa Econômica Aplicada. Boletim de Políticas Sociais - acompanhamento e análise n⿳15. Brasília. Disponível em: < http://www.ipea.gov.br/sites/000/2/publicacoes/bpsociais/ bps_15/09_desenvrural.pdf $>$, acessado em 25 de Dezembro de 2016.

LA REGIÓN RHÔNE-ALPES. Disponível em: 〈http://www.rhonealpes.fr/>, acessado em 25 de Dezembro de 2016.

NERI. M. C. et al. Microcrédito, o Mistério Nordestino e o Grammeen Brasileiro.

ORGANICS CLUSTER IN RHÔNE-ALPES. Agencio bio in RhoneAlpes. Europa Agricultura Orgânica. Biofach América Latina e Exposustentat, Nuremberg 2015.

PLANO Safra da Agricultura Familiar: após 10 anos, outra realidade. Agência Carta Maior.Disponível em: $\quad$ http://www.cartamaior.com.br/?/Editoria/Economia/Plano-Safra-da-Agricultura-Familiarapos-10-anos-outra-realidade/7/28085> Acesso em: 25 de Outubro de 2018.

PLANO Safra da Agricultura Familiar: após 10 anos, outra realidade. Relatório de Avaliação do Plano Plurianual 2008 - 2011. [S.I]: Brasília, MDA, 2009. Disponível em: <http://www.mda.gov. br/portal/publicacoes/pageflip-view?pageflip id=3638081>

POCHMANN, Marcio (Org.). Desenvolvimento, Trabalho e Solidariedade. São Paulo: Cortez Editora e Editora Fundação Perseu Abramo, 2008.

SPINK, P. K. O pesquisador conversador no cotidiano. Fundação Getulio Vargas. São Paulo. 2014. 